\title{
Evaluation of efficacy of an ultrasonic scalpel for pulmonary vascular ligation in an animal model
}

\author{
Daniel G. Nicastri, MD, ${ }^{a}$ Maoxin $\mathrm{Wu}, \mathrm{MD}, \mathrm{PhD},{ }^{\mathrm{b}}$ Jaime Yun, $\mathrm{MD},{ }^{\mathrm{c}}$ and Scott J. Swanson, $\mathrm{MD}^{\mathrm{c}}$
}

Objective: Dissection to accommodate bulky stapling devices may cause injury to pulmonary arteries in thoracoscopic lobectomies. The Harmonic Ace (Ethicon Endo-Surgery, Inc; Cincinnati, Ohio), a small ultrasonic scalpel used in systemic vessels, was tested on pulmonary vessels in pigs.

Methods: Nine pigs were assigned 1- or 6-week survival. Lobectomies were performed using the device to divide and ligate pulmonary vessels. Vessel diameter was measured, and ligation outcome was recorded. Necropsies were then performed.

Results: Permanent ligation occurred in $76 \%$ of arteries and $92 \%$ of veins. At the highest power setting, the instrument showed no failure in arteries $5 \mathrm{~mm}$ or less and veins $7 \mathrm{~mm}$ or less. Necropsies revealed no evidence of postoperative bleeding. Histopathologic analysis revealed acute coagulation necrosis at 1 week. By 6 weeks, the vessel stumps displayed features consistent with normal wound healing.

Conclusions: This device reliably divides pulmonary vessels $4 \mathrm{~mm}$ and smaller, typically encountered in pig lobectomies. Higher power settings and operator experience may increase effectiveness. Further testing is necessary to delineate the device's limitations before potential use in human pulmonary vasculature.

From the Departments of Surgery, ${ }^{a}$ Pathology, ${ }^{\mathrm{b}}$ and Thoracic Surgery, ${ }^{\mathrm{c}}$ Mount Sinai Medical Center, New York, NY.

Ethicon Endo-Surgery, Inc (Cincinnati, Ohio) provided funding for this project. The Harmonic Ace and power source were donated for use with this project. The authors had full control of the design of the study, methods used, outcome parameters, analysis of the data, and production of the written report.

Received for publication Nov 28, 2006; revisions received Feb 7, 2007; accepted for publication Feb 12, 2007.

Address for reprints: Scott J. Swanson, MD, Mount Sinai Medical Center, 1190 Fifth Avenue, New York, NY 10029 (E-mail: scott. swanson@mountsinai.org).

J Thorac Cardiovasc Surg 2007;134:160-4

$0022-5223 / \$ 32.00$

Copyright (๑) 2007 by The American Association for Thoracic Surgery

doi:10.1016/j.jtcvs.2007.02.015
$\mathrm{T}$ he drive for less-invasive surgical techniques is accompanied by a race to create smaller and more effective surgical instruments. In thoracic surgery, video-assisted thoracoscopic surgery lobectomy is becoming more prevalent for the treatment of lung cancer. Although it has not been proven superior to conventional lobectomy by a large randomized prospective series, there is evidence that it has comparable safety, efficacy, and survival results in stage I lung cancer. ${ }^{1,2}$ Despite this evidence, the surgery routinely takes longer than does lobectomy by thoracotomy, even in the most skilled hands. Improving instruments may decrease the length of time under anesthesia and make the surgery safer. Currently, endoscopic stapling devices that simultaneously divide and ligate are used for the major pulmonary vessels during a lobectomy. However, dissection to accommodate the bulky stapling device may lead to avulsion of a pulmonary artery. One particularly difficult area of dissection involves the right upper lobe posterior ascending pulmonary artery during a video-assisted thoracoscopic surgery lobectomy. For this reason, we hypothesized that a small handheld ultrasonic scalpel may be more safe, efficient, and effective than the current standard in pulmonary vascular dissection, division, and ligation. The Harmonic Ace (Ethicon Endo-Surgery, Inc, Cincinnati, Ohio) has been used extensively in human patients for general surgical procedures (Figure 1). However, pulmonary arteries are less muscular and more elastic than systemic vessels, such as the inferior mesenteric arteries. For this reason, ligation with an ultrasonic scalpel should be studied extensively. Failure to ligate these vessels could lead to life-threatening hemorrhage. Our study reports testing of the Harmonic Ace for dividing and ligating measured pulmonary vessels during lobectomies in an animal model. 


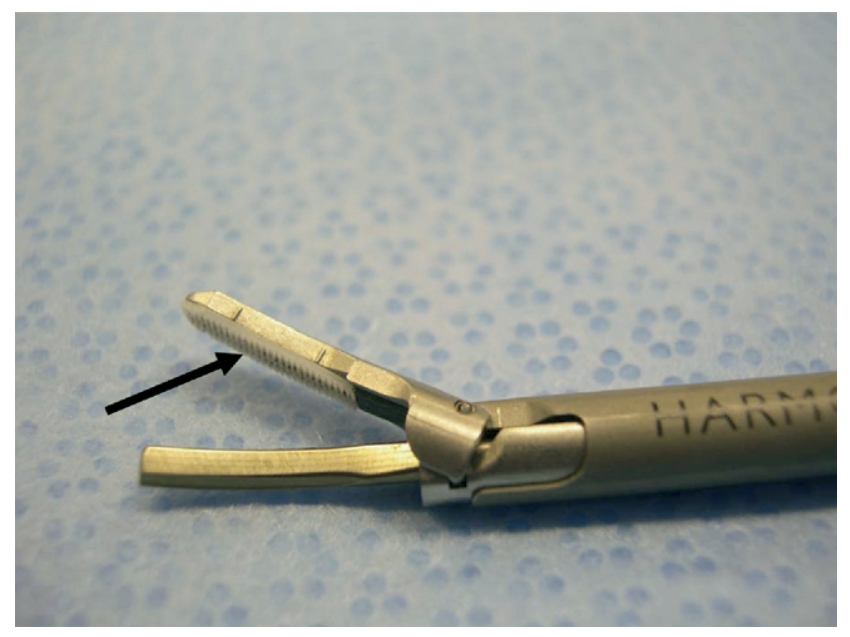

Figure 1. The Harmonic Ace (Ethicon Endo-Surgery, Inc; Cincinnati, Ohio) is a small handheld ultrasonic scalpel. The blade jaws have 2 lines that indicate a $5-\mathrm{mm}$ diameter. Notice the small fibers on the superior blade (arrow).

\section{Materials and Methods}

This prospective study was designed with the goal of performing lobectomies in pigs with the use of the Harmonic Ace to divide and ligate the pulmonary vessels.

\section{Ultrasonic Scalpel}

The handheld and hand-activated ultrasonic scalpel clamps on vessels with its "blades" when the handle is squeezed (Figure 1). Electrical energy is passed into the handpiece from the attached power source. It is then converted to mechanical energy, vibrating longitudinally at a maximum frequency of 55,000 cycles per second. The pressure from the clamp, or "grip force," combined with the generation of heat, coapts vessels. Heat generation ranges between temperatures of $50^{\circ} \mathrm{C}$ and $100^{\circ} \mathrm{C}$, denaturing proteins and forming a coagulum while division also occurs. ${ }^{3}$

\section{Animals}

All aspects of the study were approved by the Institutional Animal Care and Use Committee. A total of 9 pigs underwent right-sided lobectomies. The animals were healthy male and female pigs weighing approximately 30 to $35 \mathrm{~kg}$. The pigs were assigned to survival times of 1 week or 6 weeks before operation.

\section{Perioperative Care, Postoperative Care, and Euthanasia}

Animals were anesthetized with isoflurane and ketamine and intubated with double-lumen tubes. Intraoperative, perioperative, and postoperative analgesia were provided using buprenorphine, fentanyl patch, and flunixin. Oxygen saturation was monitored during the entire procedure. For the last 2 operations, before vessel division, pulmonary artery pressures were measured to estimate the pressure typically encountered by the newly divided arteries. Chest tubes were removed in the early postoperative period. Animals were given antibiotics perioperatively and postoperatively
TABLE 1. Results of division of pulmonary arteries

\begin{tabular}{|c|c|c|c|c|c|}
\hline \multicolumn{6}{|c|}{ Pulmonary arteries } \\
\hline $\begin{array}{l}\text { Diameter } \\
\text { (mm) }\end{array}$ & Total & No seal* & $\begin{array}{c}\text { Temporary } \\
\text { sealt }\end{array}$ & $\begin{array}{l}\text { Permanent } \\
\text { seal‡ }\end{array}$ & $\begin{array}{c}\text { Seal } \\
\text { percentage }\end{array}$ \\
\hline 1 & 1 & & & 1 & $100 \%$ \\
\hline 2 & 3 & & & 3 & $100 \%$ \\
\hline 3 & 5 & & & 5 & $100 \%$ \\
\hline 4 & 8 & & & 8 & $100 \%$ \\
\hline 5 & 4 & 2 (PS2, PS2) & 1 (PS2) & 1 & $25 \%$ \\
\hline 6 & 0 & & & & \\
\hline 7 & 3 & & 2 (PS2, PS5) & 1 & $33 \%$ \\
\hline 8 & 0 & & & & \\
\hline 9 & 1 & & 1 (PS5) & & $0 \%$ \\
\hline Total & 25 & 2 & 4 & 19 & $76 \%$ \\
\hline
\end{tabular}

$P S$, Power setting for ligation failures in parentheses. *No seal: Harmonic ligation failed immediately on specimen or pig side and was sutured. tTemporary seal: Harmonic ligation failed intraoperatively and was sutured. ¥Permanent seal: Harmonic ligation permanent as determined at necropsy. There were 6 vessels that were not ligated permanently. Power setting was a factor because the highest power setting (PS5) sealed all vessels up to $5 \mathrm{~mm}$ in diameter and 1 that was $7 \mathrm{~mm}$ in diameter. PS5 failed once on a 7-mm vessel. Power setting 2 (PS2) failed 3 times on the 5-mm diameter vessels.

for 10 days. Euthanasia was carried out with an anesthetic overdose of pentobarbital at the predetermined interval of 1 or 6 weeks.

\section{Operation, Vascular Ligation, and Division}

A standard posterolateral thoracotomy was performed on each pig. The vessels to the targeted lobes were identified, isolated, and measured. They were then divided using various power settings on the Harmonic Ace. The outcome of the vessel's ligation was recorded as "no seal," "temporary seal" (if the vessel began bleeding during the operation), or "permanent seal." Lobectomies were completed in standard fashion, dividing vessels with the ultrasonic scalpel and stapling the bronchi. Vessels that were not ligated by the device were recorded accordingly and oversewed with sutures.

\section{Pathologic analysis}

Necropsies were performed on every animal after euthanasia to identify whether bleeding had occurred. If there was no evidence of bleeding, the divided vessels were then recorded as a "permanent seal." Vessel specimens were procured at necropsies, as well as 1 "normal" pulmonary vein and artery from a single animal's operation. They were placed in $10 \%$ formalin and processed in routine fashion for human tissue samples. Hematoxylin-eosin-stained slides were made from cross-sections of the recovered divided vessels.

\section{Results}

\section{Ligation}

Overall, the device permanently sealed $76 \%$ of pulmonary arteries (Table 1) and 92\% of pulmonary veins (Table 2) that were encountered when performing these right-sided lobectomies. However, there were limitations for this device with regard to the size of the vessel. The device sealed all 
TABLE 2. Results of division of pulmonary veins

\begin{tabular}{|c|c|c|c|c|c|}
\hline \multicolumn{6}{|c|}{ Pulmonary veins } \\
\hline $\begin{array}{l}\text { Diameter } \\
(\mathrm{mm})\end{array}$ & Total & No seal* & $\begin{array}{c}\text { Temporary } \\
\text { sealt }\end{array}$ & $\begin{array}{c}\text { Permanent } \\
\text { seal‡ }\end{array}$ & $\begin{array}{c}\text { Seal } \\
\text { percentage }\end{array}$ \\
\hline 1 & 2 & & & 2 & $100 \%$ \\
\hline 2 & 5 & & & 5 & $100 \%$ \\
\hline 3 & 7 & & & 7 & $100 \%$ \\
\hline 4 & 3 & & & 3 & $100 \%$ \\
\hline 5 & 5 & 1 (PS2) & & 4 & $80 \%$ \\
\hline 6 & 0 & & & & \\
\hline 7 & 2 & & & 2 & $100 \%$ \\
\hline 8 & 1 & 1 (PS5) & & & $0 \%$ \\
\hline Total & 25 & 2 & & 23 & $92 \%$ \\
\hline
\end{tabular}

$P S$, Power setting for ligation failures in parentheses. * No seal: Harmonic ligation failed immediately on specimen or pig side and was sutured. †Temporary seal: Harmonic ligation failed intraoperatively and was sutured. $\ddagger$ Permanent seal: Harmonic ligation permanent as determined at necropsy. There were only 2 ligation failures in pulmonary veins occurring on a $5-\mathrm{mm}$ vessel and an 8-mm vessel. The highest, fastest power setting (PS5) allowed permanent ligation of vessels as large as $7 \mathrm{~mm}$ in diameter.

pulmonary vessels less than $4 \mathrm{~mm}$ in diameter that were encountered. At a diameter of $5 \mathrm{~mm}$ and greater, factors such as the power setting and size of the actual "blades" of the ultrasonic scalpel seemed to play a role. The mean pulmonary artery pressure for 2 animals was $13 \mathrm{~mm} \mathrm{Hg}$, and the mean systemic pressure at the time of measurement while under anesthesia was $50 \mathrm{~mm} \mathrm{Hg}$.

\section{Power Setting}

The power setting adjustments on the Harmonic Ace range from 1 to 5. Power setting affects the speed of cutting and quality of hemostasis. Level 5 should provide the fastest cutting, but perhaps the least hemostasis. ${ }^{3}$ We began our study at power setting 2. After experiencing the device "sticking" to the coagulum on the vessels, we changed our technique. We started division at level 2, releasing the device from the vessels at level 5. By the fourth operation, we performed every division and ligation on power setting 5 . From this point on, the device was able to seal all encountered vessels with a diameter less than $5 \mathrm{~mm}$.

\section{Pathologic analysis}

Necropsies were performed on each pig after euthanasia. Of 9 animals, 5 were assigned to 1 -week survival and 4- to 6-week survivals. The second pig (assigned to 1-week survival) was sacrificed in the early postoperative period because the device failed to ligate the 2 pulmonary vessels ("no seal") and the stumps had to be oversewn immediately, nullifying the testing variables in this animal. For this reason, the pig was euthanized. There was no evidence of hemorrhage in any of the 9 necropsies. One of the 6-week survival pigs was euthanized at 3 weeks after experiencing

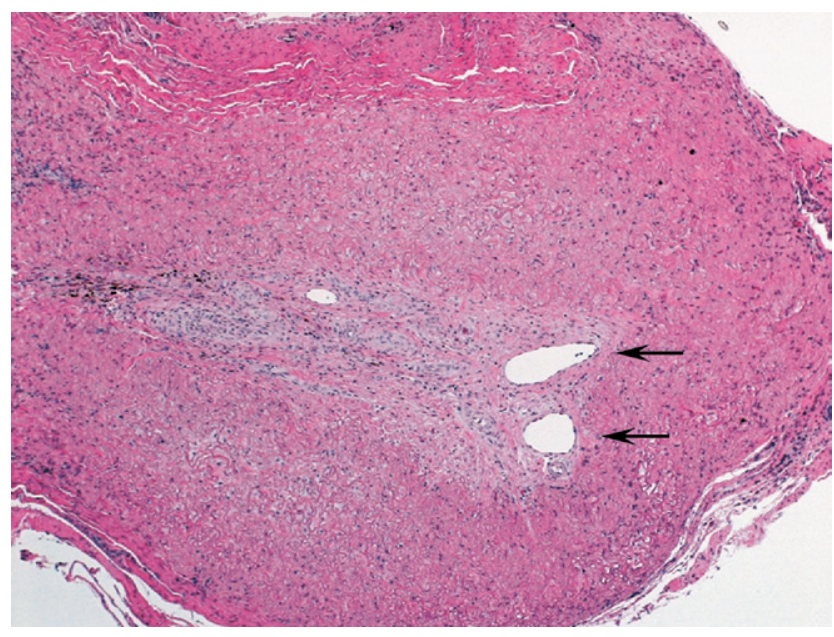

Figure 2. At 6 weeks, the lumen is almost completely closed, with the exception of occasional blood vessels (arrows), similar to an immature scar (hematoxylin-eosin: 50X magnification).

respiratory distress. An empyema was discovered on necropsy. Histology was taken from all identified vessel stumps on necropsy. One-week slides revealed a coagulation necrosis at the "charred" area of the vessel stump. Also noted were foreign body granulomas presumed to be formed around the fibers from the blades of the instrument. In 1 specimen, elements of papillary endothelial hyperplasia were also seen. Papillary endothelial hyperplasia may represent organization and recanalization of a thrombus, although its significance is unclear. ${ }^{4,5}$ By 3 and 6 weeks, collagen was laid down and normal wound healing was appreciated (Figure 2).

\section{Discussion}

The use of an ultrasonic scalpel in thoracic surgery has been reported before. Aoki and Kaseda ${ }^{6}$ used a device for thoracoscopic wedge resections. However, they did not use the device for pulmonary vascular ligation. Our results suggest that at the highest power setting (5), an experienced operator can reliably ligate all pulmonary vessels $4 \mathrm{~mm}$ in diameter and less in a pig model by using an ultrasonic scalpel.

\section{Analysis of Quantitative Results}

The device was tested with the specific goal of determining its limitations in ligating pulmonary arteries during porcine lobectomies. In addition, we sought to establish the ideal parameters for successful ligation. In pulmonary arteries, the ultrasonic scalpel permanently sealed $76 \%$ of all arteries encountered and $100 \%$ (17/17) of those arteries that were $4 \mathrm{~mm}$ and less. This result was achieved at all power settings. For 5-mm vessels, a permanent seal occurred in $25 \%(1 / 4)$. Of the 8 arteries greater than $4 \mathrm{~mm}$ in size, only 


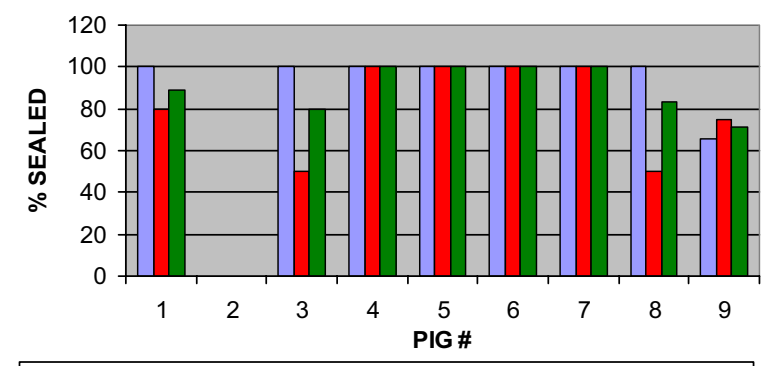

$\square \%$ VEINS SEALED $\square$ \%ARTERIES SEALED $\square \%$ TOTAL SEALED

After the third operation, the power setting was changed to the highest, fastest, ligation setting (PS5). The only ligation failures following this change occurred in vessels larger than $5 \mathrm{~mm}$ in diameter (operation \#8 and \#9).

Figure 3. Percentage of vessels sealed for 9 operations.

2 were permanently sealed. Of note, the successful seals occurred at power setting 5 , whereas the immediate failure and temporary seal occurred at power setting 2 (Table 1). In fact, at power setting 5, a permanent seal was achieved in all tested vessels with the exception of one 7-mm vessel and one $90-\mathrm{mm}$ vessel. The device permanently sealed $92 \%$ of all veins encountered. There was only 1 failure for veins $7 \mathrm{~mm}$ and less. This occurred at power setting 2 (Table 2). At level 5, the setting used from the fourth operation on, all vessels $5 \mathrm{~mm}$ in diameter and smaller were successfully and permanently ligated (Figure 3). Of the 8 vessels greater than $4 \mathrm{~mm}$ that we encountered, 6 were sealed permanently.

\section{Technical Factors}

On the basis of our data, the device sealed $100 \%$ of pulmonary arteries encountered that were $4 \mathrm{~mm}$ or less in diameter when the ideal power setting was used. Furthermore, at least a temporary seal occurred in most vessels $(46 / 50 ; 92 \%)$. A temporary seal may be useful in difficult thoracoscopic dissections. A temporarily sealed vessel can be ligated later with a surgical clip once the finer dissection is accomplished. The goal, however, is to achieve $100 \%$ success. None of the device failures occurred late. All occurred during the operation so there were no instances of bleeding after closure. This was confirmed by necropsy, which demonstrated no evidence of hemothorax, a complication of late failure.

In our animal model, several factors affected the success of ligation. These were related to the size of the vessel and various aspects of operator experience. Clamp pressure is probably inadequate at the distal end (relative to the scalpel blades) in larger vessels. The larger stumps that ruptured intraoperatively after either a "no seal" or "temporary seal" did so at the distal end of the blades. In a limited sample, we attempted to reclamp the distal end, either before rupture or after rupture. None of these efforts formed permanent seals in the largest vessels. In fact, longer scalpel blades, if capable of maintaining adequate clamp pressure, may be better for larger vessels.

Pulmonary artery pressures may also affect the likelihood of success. The recorded porcine mean pulmonary pressures of $13 \mathrm{~mm} \mathrm{Hg}$ are lower than those typically encountered in a human undergoing lobectomy. The mean pulmonary pressure in normal adults is approximately $15 \mathrm{~mm} \mathrm{Hg}{ }^{7}$ Patients undergoing lobectomies often have elevated pulmonary pressures secondary to their disease states. Higher pressures may affect vascular ligation, although this was not tested. The sizes of the vessels encountered in the porcine model are similar to those of the segmental pulmonary arterial branches encountered in human lobectomies, particularly those of the right upper lobe posterior ascending artery.

With regard to operator experience, other important factors were common to general surgical technique. This includes minimizing tension. Tension was most effectively minimized when the operator also relaxed his or her arm, while keeping a good seal on the vessel, and moved with "beat-to-beat" variation. This "beat-to-beat" movement is more significant in pulmonary vasculature as opposed to systemic because of the proximity to the heart. Finally, the issue of power setting may be related to "beat-to-beat" variation as well. The highest power setting (5), noted for the fastest cutting, ligated most effectively. Faster cutting may cause less shearing on the stumps and coagulum because of the shorter duration of "beat-to-beat" movement.

\section{Pathologic analysis}

The effects of an ultrasonic scalpel on systemic vessel closure have been reported by Foschi and colleagues. ${ }^{8}$ Their findings suggested a mechanism of vessel closure based on compression followed by heat generation. The heat generation theoretically breaks tertiary hydrogen bonds between the collagen and the extracellular matrix proteins. The proteins are denatured and may form an insoluble gel sealing the vessel. ${ }^{8,9}$ Our results clearly demonstrated coagulation necrosis near the vessel stump, which combined with protein denaturation can seal a vessel. The lower operating temperature of this device $\left(80^{\circ} \mathrm{C}-90^{\circ} \mathrm{C}\right)$, compared with that used by electrocautery, may limit "charring" to the immediate area of division. ${ }^{10}$ Therefore, this should limit damage to nearby structures, such as other pulmonary arterial or venous branches and the bronchi, while dividing and sealing.

\section{Future Studies}

Additional studies could include a prospective randomized study comparing the standard stapling devices with the ultrasonic scalpel. Ten pigs could be used to compare one 
technique versus the other, with each animal serving as its own control with subsequent statistical analysis. In another study, the pulmonary artery pressures could be investigated. Pulmonary arterial pressures could be manipulated with vasopressors and invasive monitors, that is, placing an arterial line directly into the main pulmonary artery around the time of division. The effects of a longer bladed device and its ability to seal larger vessels could be investigated in yet another study. After a favorable statistical analysis comparing the ultrasonic scalpel with the "gold standard" of stapling devices, one may be able to confidently test this on humans. At first, during thoracotomy procedures, the device could be used to divide vessels. These ligated vessels would be monitored by the surgeon throughout the procedure. Before closing, a clip could be placed over the vessels. Eventually, there could be a progression to using these devices thoracoscopically.

\section{Conclusions}

By using this animal model, vessels $4 \mathrm{~mm}$ and smaller were reliably divided in pig lobectomies. Further determination of the device's limitations should be investigated before attempting use in human pulmonary vasculature.

\section{References}

1. McKenna RJ Jr, Houck W, Fuller CB. Video-assisted thoracic surgery lobectomy: experience with 1,100 cases. Ann Thorac Surg. 2006;81: 421-5.

2. Walker WS, Codispoti M, Soon SY, Stamenkovic S, Carnochan F, Pugh G. Long-term outcomes following VATS lobectomy for nonsmall cell bronchogenic carcinoma. Eur J Cardiothorac Surg. 2003; 23:397-402.

3. Harmonic Scalpel® Ethicon Endo-Surgery, Inc., Johnson \& Johnson GATEWAY®, [Internet] c2006. Available at: http://www.jnjgateway. com/home.jhtml loc $=$ USENG\&page $=$ viewContent $\&$ contentId $=$ 09008b9880a2d37a\&parentId=09008b9880a2ba17). Accessed May 24, 2006.

4. Rosai J. Soft tissues. In: Rosai J, ed. Ackerman's Surgical Pathology. New York, NY: Mosby; 1996:2064-121.

5. Albrecht S, Kahn HJ. Immunohistochemistry of intravascular papillary endothelial hyperplasia. J Cutan Pathol. 1990;17:16-21.

6. Aoki T, Kaseda S. Thoracoscopic resection of the lung with the ultrasonic scalpel. Ann Thorac Surg. 1999;67:1181-3.

7. Heck H, Levitzky M. The respiratory system. In: O'Leary JP, ed. The Physiologic Basis of Surgery. 3rd Edition. Philadelphia, PA: Lippincott Williams and Wilkins; 2002:424.

8. Foschi D, Cellerino P, Corsi F, Taidelli T, Morandi E, Rizzi A, et al. The mechanisms of blood vessel closure in humans by the application of ultrasonic energy. Surg Endosc. 2002;16:814-9.

9. Kinoshita T, Kanehira E, Omura K, Kawakami K, Watanabe Y. Experimental study on heat production by a $23.5-\mathrm{kHz}$ ultrasonically activated device for endoscopic surgery. Surg Endosc. 1999;13:621-5.

10. Lantis JC II, Durville FM, Connolly R, Schwaitzberg SD. Comparison of coagulation modalities in surgery. J Laparoendosc Adv Surg Tech A. 1998;8:381-94. 